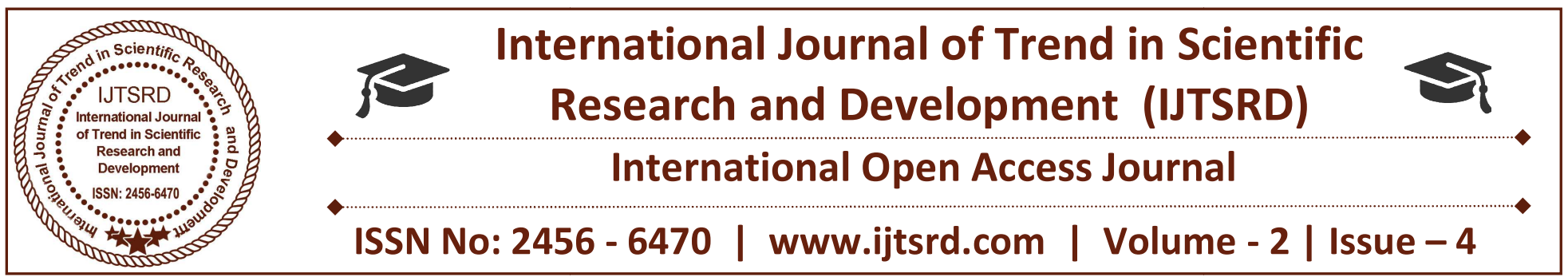

\title{
A Review on Cosmetic Preparation of Hair
}

\author{
Abujam Nganthoi Devi, Zakariya Noorani, Gaurav Kumar Sharma \\ Faculty of Pharmaceutical Sciences, Mewar University, Gangar, Chittorgarh, Rajasthan, India
}

\begin{abstract}
Hair is an integrated system with a particular chemical and physical behaviour. It is a complex structure of several morphological components that act as unit and has several functions, from protecting of skins to sexual and social communications. In literature, there are various study about hair that take into consideration different aspects within many fields of science, including biology, dermatology, cosmetics ,forensic science and medicine. These review the formulations and mode of action of hair cosmetics, summarized the principal anatomicalen and physiological aspect of different types of human hair, hair growth cycle, hair porosity. This review could be the basic improvement and progression in the field of hair research.
\end{abstract}

Keywords: Hair, Hair cosmetic, shampoo, hair dyes, hair conditioner, Hair growth cycle, Hair porosity, Anatomy of hair

\section{INTRODUCTION}

Hair has two parts the follicle is in the skin and the shaft which is visible above the head. The hairs follicle has several layers with different function: substance that help to prevent hair and skin drying out. The origin of hair by week22, developing fetus has all of its hair follicle form.

At this stage of life there are about 5millio hair follicles on the body. There are total of one million on the head, with one hundred thousand of those follicles residing on the scalp. This is the largest number of hair follicles a human will ever have, since we don't generate new hair follicles during the course of our live. [1,2]

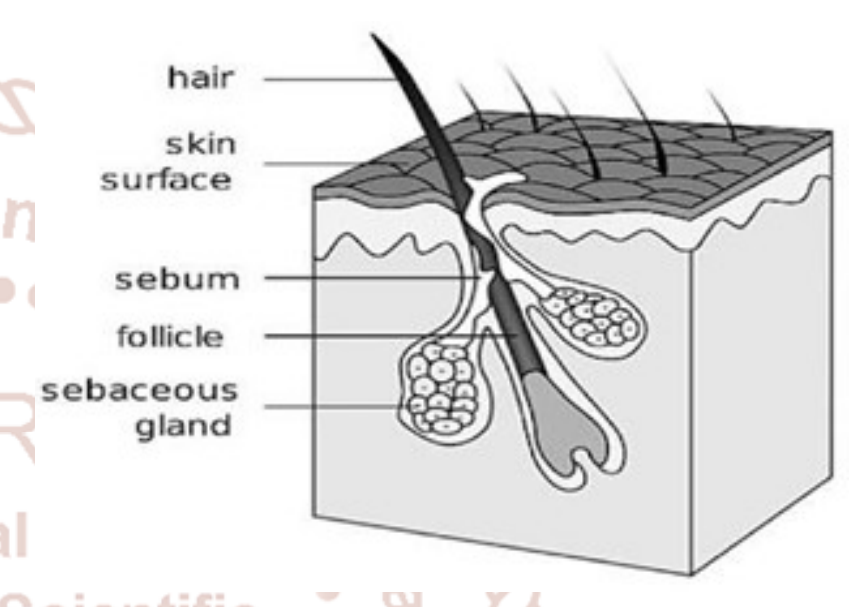

Fig1: structure of hair

\section{COMPONENT OF HAIR:}

Hairs contain water, lipid, trace of mineral elements and melanin[3] but the main component of hair is a hard protein is actually called as keratin. The hair shaft is made of keratin. This protein is actually dead, so the hair that we actually see is dead.

\section{HAIR COLOUR:}

Melanin is responsible for natural colour of hair. This process occurs in the hair root during hair development. There are two types of melanin: eumelanin (dark) and phepomelanin (light). The level of melanin can very over time causing a person's hair to change colour and it is possible to have follicles to have with different combinations of melanin.[5-6]

\section{Why hair colour is different?}

Hair colour is the pigmentation of hair follicles due to two types of melanin: eumelanin and pheomelanin. Generally, if more eumelanin is present, the colour of the hair is darker; if less eumelanin is present, the hair is lighter. The darker a person's natural hair colour, the more individual hair follicles they have on their 
scalp. Levels of melanin can vary over time causing a person's hair colour to change, and it is possible to have hair follicles of more than one colour on the same person. Particular hair colours are associated with ethnic groups. Gray or white hair is associated with age.[4]

\section{Genetic and biochemistry of hair colour:}

The genetics of hair colours are not yet firmly established. According to one theory, at least two gene pairs control colour. One phenotype (brown/blonde) has a dominant brown allele and a recessive blond allele. A person with a brown allele will have brown hair; a person with no brown alleles will be blond. This explains why two brown-haired parents can produce a blond-haired child. However, this can only be possible if both parents are heterozygous in hair colour- meaning that both of them have one dominant brown hair allele and one recessive allele for blond hair, but as dominant traits mask recessive ones the parents both have brown hair. The possibility of which trait may appear in an offspring can be determined with a Punnett square.[7]

\section{Hair Growth Cycle}

Hair on the scalp grows about 3 to $.4 \mathrm{~mm} /$ day or about 6 inches per year. Unlike other mammals, human hair growth and shedding is random and not seasonal or cyclical. At any given time, a random number of hairs will be in one of three stages of growth and shedding: anagen, catagen, and telogen.

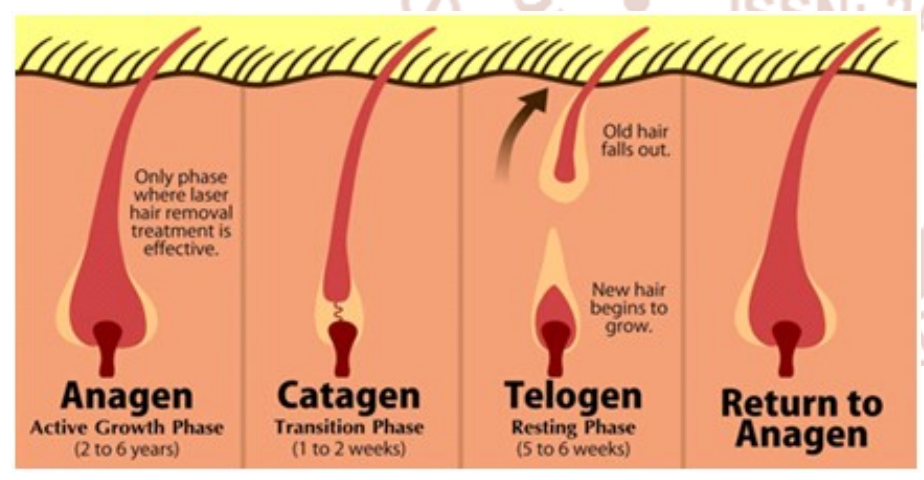

Fig2: Hair growth cycle

\section{Anagen}

Anagen is the active phase of the hair. The cells in the root of the hair are dividing rapidly. A new hair is formed and pushes the club hair (a hair that has stopped growing or is no longer in the anagen phase) up the follicle and eventually out.

During this phase the hair grows about $1 \mathrm{~cm}$ every days. Scalp hair stays in this active phase of growth for two to six year. Some people have difficulty growing their hair beyond a certain length because they have a short active phase of growth. On the other hand, people have long active phase of Anagen

Anagen is the active phase of the hair. The cells in the root of the hair are dividing rapidly. A new hair is formed and pushes the club hair (a hair that has stopped growing or is no longer in the anagen phase) up the follicle and eventually out.

The hair on the arms, legs, eyelashes, and eyebrows have a very short active growth phase of about 30 to 45 days, explaining why they are so much shorter than scalp hair.

\section{Catagen}

The catagen phase is a transitional stage and about $3 \%$ of all hairs are in this phase at any time. This phase lasts for about two three weeks. Growth stops and the outer root sheath shrinks' and attaches to the root of the hair. This is the formulation of what is known as a club hair.

\section{Telogen}

Telogen is the resting phase and usually accounts for $6 \%$ to $8 \%$ of all hairs. This phase lasts for about 100 days for hairs on the scalp and longer for hairs on the eyebrow, eyelash, arm, and leg. During this phase, the hair follicle is completely formed. Pulling out a hair in this phase will reveal a solid, hard, dry, white material at the root. About 25 to 100 telogen hairs shed normally each day.[8]

\section{Why don't we have hair on palms?}

The main functional reason is we need to be able to grip things with our hands (and feet, which are also hairless), and hair would interfere with that. Physiologically, the epidermis in these parts of the body is very thick and highly keratinized, and when combined with the thick under laying layer of dermis, this results in skin that does not support the growth and maturation of hair follicles

Typically, people don't grown hair on the soles of our feet or palms of our hands. This is because this skin on these parts lacks hair follicles, and does not therefore produce hair.[9]

Hair porosity: Hair porosity refers to how much moisture it certain. Certain hair types like curly hair may be impacted by porosity more than others due to a lack of moisture, but porosity can impact other hair 
in different ways"[9]. Hair porosity can be determines by using three methods:

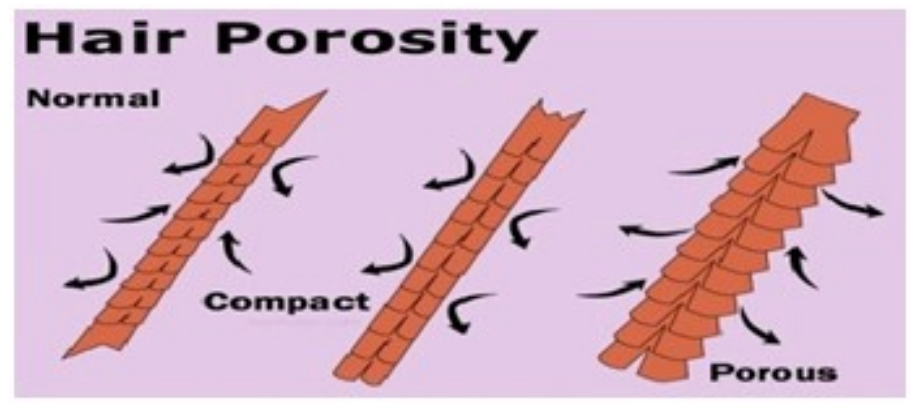

Fig3: hair porosity

1. The float test: Take a couple of hair strands of hair from the comb or brush and drop them into a bowl of water. Let them sit for 2-4minutes. If the hair is floated, that means low porosity. If it sinks, that is high porosity.

2. The slip'n'slide test: Take a hair strand of hair and slide the fingers up the shaft. If you feel little bumps along the way, this means that your cuticle is lifted and that you have high porosity. If the fingers slip smoothly, then it has low porosity hair[10].

3. "The spray bottle test: take a small section of hair and pin the rest back. Spray that section with a little water and mist it. If the water sits on the top of hair beads up, i.e. low porosity hair. If hair absorb the water quickly I.e. high porosity hair. If the water sits on the hair for several minutes then is absorbed i.e. normal porosity hair".[11]

\section{Hair cosmetics}

\section{SHAMPOOS}

"Shampoos are not only scalp cleaners, but indubitably act as preventing the hair shaft damage. Many scalp diseases are also treated by active ingredients that are added to the shampoo's formulations. Shampoos are typically composed of 10-30 ingredients although products with as few as four ingredients are available are: (1) Cleansing agents; (2) additives that contribute to the stability and comfort of the product; (3) conditioning agents, intended to impart softness and gloss, to reduce flyaway and to enhance disentangling facility, and (4) special care ingredients, designated to treat specific problems, such as dandruff and greasy hair.”[12]

\section{Formulation of shampoo}

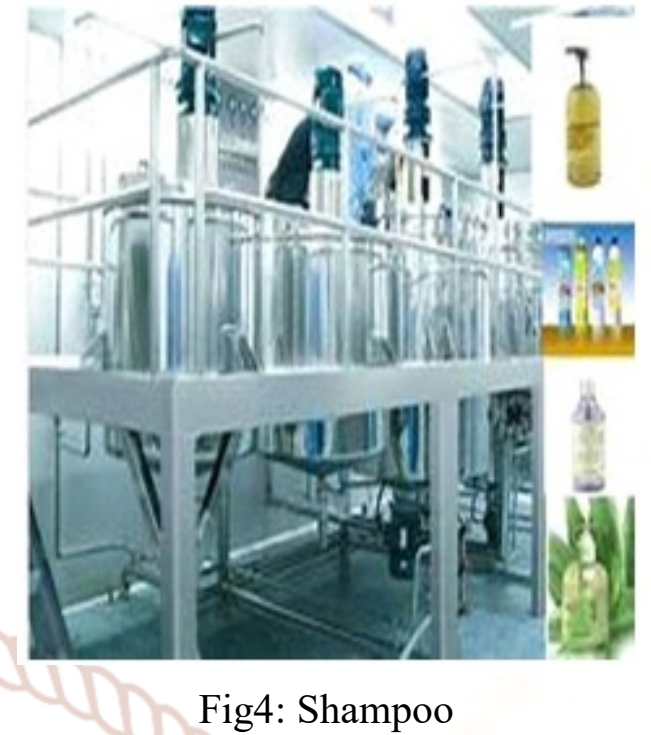

1. "Preservative: Anionic surfactant, Example:

Sodium Lauryl Sulphate

2. Conditioning agent: improve manageability, feel and lustre of hair, Example: Lanoline, Mineral oil, Egg albumin, Amino acids, Lecithin and herbal extract like Shikakai and Henna.

3. Thickening agent: make shampoo viscous so that they are easy to pour and handle. Example Gum, CMC,HPMC, PVA, carbopol 934p etc.

4. Chelating agent: prevent deposition of calcium and magnesium salt of soap on hairs. Examples: Disodium edetate, polyphosphates, citric acid, etc.

5. Antidandruff agent: zinc pyridium thiol-N-oxide (ZPTO), Selenium sulphide, bithinol, resorcinol, etc."[21]

\section{Types of shampoo:}

- "Liquid shampoo

- Powder shampoo

- Cream shampoo

- Gel based shampoo

\section{Evaluation of shampoo:}

1. Changing powder

2. Foaming powder

3. eye erretation potential.[13] 
International Journal of Trend in Scientific Research and Development (IJTSRD) ISSN: 2456-6470

FORMULATIONS OF SHAMPOO

ACCORDING TO THEIR CLASSIFICATION:

\section{POWDER SHAMPOO}

\begin{tabular}{|l|l|}
\hline Henna powder & $5 \%$ \\
\hline Soap powder & $50 \%$ \\
\hline Sodium carbonate & $22.5 \%$ \\
\hline Borax & $15 \%$ \\
\hline & q.s \\
\hline
\end{tabular}

CREAM SHAMPOO

\begin{tabular}{|l|l|}
\hline SLS & $38 \%$ \\
\hline Cetyl alcohol & $7 \%$ \\
\hline Water Upto & $100 \%$ \\
\hline Color, perfume & q.s \\
\hline LIQU
\end{tabular}

\section{LIQUID SHAMPOO}

\begin{tabular}{|l|l|}
\hline SLS & $40 \%$ \\
\hline NaCl (to desired viscosity) & $2-4 \%$ \\
\hline Water Upto & $100 \%$ \\
\hline Perfume, color, preservatives & q.s \\
\hline Preservative & Q.s \\
\hline
\end{tabular}

JELLY SHAMPOOS

Alkyl dimethyl benzalkonium chloride

TLS

Coconut ditethanolamide

HPMC

Water

Color, perfume, preservative

\section{AEROSOL SHAMPOO}

\begin{tabular}{|l|l|}
\hline TLS & $60 \%$ \\
\hline Coconut diethanolamide & $2 \%$ \\
\hline Water & Upto $90 \%$ \\
\hline Propellent & $10 \%$ \\
\hline Color, perfume, preservative & $\mathrm{q} . \mathrm{s}$ \\
\hline ANTI-DANDRUFF SHAMPOO & \multicolumn{1}{|l|}{} \\
\hline Thymol & $0.05 \%$ \\
\hline Menthol & $0.1 \%$ \\
\hline Camphor & $0.1 \%$ \\
\hline TLS & $55 \%$ \\
\hline Water upto & $100 \%$ \\
\hline Color, perfume, preservative & $\mathrm{q} . \mathrm{s}$ \\
\hline
\end{tabular}

\section{TWO LAYER SHAMPOO}

Cocamidopropylamine oxide

Lauramine DEA

Lactic acid $(50 \%)$

Formaldehyde

\section{ANTI-DANDRUFF SHAMPOO}

\begin{tabular}{|l|l|}
\hline Selenium sulfide & $2.5 \%$ \\
\hline Bentonite & $5 \%$ \\
\hline SLS paste & $35 \%$ \\
\hline Water upto & $100 \%$ \\
\hline
\end{tabular}

\begin{tabular}{|c|c|}
\hline Color, perfume, preservative & q.s \\
\hline \multicolumn{2}{|l|}{ HERBAL SHAMPOO } \\
\hline Natural essential oil blend & $0.5 \%$ \\
\hline Cyamopsis tetragonoloba (Guar Gum) & $1 \%$ \\
\hline Camellia sinensis (Green Tea) extract & $2 \%$ \\
\hline Glycerin & $1 \%$ \\
\hline Hydrolysed wheat protein & $2.5 \%$ \\
\hline Salvia officinalis (Sage) leaf extract & $1.5 \%$ \\
\hline Salvia officinalis (Sage) & $1.5 \%$ \\
\hline Glyceryl oleate & $1 \%$ \\
\hline Polysorbate 20 & $0.5 \%$ \\
\hline Potassium sorbate & $5 \%$ \\
\hline Aloe barbadensis (Aloe vera) extract & $0.5 \%$ \\
\hline Arctium minus (Burdock) root extract & $0.5 \%$ \\
\hline $\begin{array}{l}\text { Disodium coco-glucoside } \\
\text { sulfosuccinate }\end{array}$ & $0.5 \%$ \\
\hline Preservatives & q.s \\
\hline Water Upto & $100 \%$ \\
\hline
\end{tabular}

\section{Hair Dyes}

Fig5: Hair dye

Definition: Hair colourants are the cosmetic preparations which are used by men and women either to change the natural hair colour or to mask grey hair. The properties of typical hair colourants are

The formulation of the hair colourant should be stable.

They should colour the hair evenly.

$>$ They should not lead to loss of the natural shine of hair.

The shaft of the hair must not be damaged.

$>$ The natural moisture of the hair must not be lost.

$>$ Must possess properties like non-irritant and nonsensitizing. 
Must be non-toxic in nature. Must impart stable color to the hair.

1. Temporary Hair Colorants: They are leave-in preparations. The hair is not rinsed after the application of the colorant. The colorant is easily removed with one wash using a shampoo because they are absorbed in to the cuticle and cannot enter into the cortex of the hair. They are rarely called as water rinses.

\section{(a) Powder Formulations:}

\begin{tabular}{|l|l|}
\hline \multicolumn{1}{|c|}{ Formula } & \multicolumn{1}{|c|}{ Quantity for $\mathbf{1 0 0} \mathrm{g}$} \\
\hline Certified color & $5 \mathrm{~g}$ \\
\hline Tartaric acid (buffer) & $95 \mathrm{~g}$ \\
\hline
\end{tabular}

\section{Semi-permanent Hair Colourants / Direct Dyes}

Ingredient: The semi-permanent hair colourants are composed of the following constituents.
(a) Dye
(b) Water
(c) Organic solvent like alcohol, derivatives of glycol.
(d) Fatty acid, fatty acid amide.
(e) Thickener.
(f) Surfactant
(g) Perfume
(h) Aliphatic primary amines which work as co- solvent and buffer.

\begin{tabular}{|l|l|}
\hline \multicolumn{1}{|c|}{ Formula } & Quantity for $100 \mathrm{~g}$ \\
\hline Acid dyestuff (color) & $6 \mathrm{~g}$ \\
\hline Alcohol (antiseptic & $10 \mathrm{~g}$ \\
\hline $30 \%$ acetic acid (buffer & $10 \mathrm{~g}$ \\
\hline Water (solvent) & $74 \mathrm{~g}$ \\
\hline
\end{tabular}

\section{(A) Dyes:}

The dyes which impart different shades belong to the following categories:

\section{(B) Colour Shampoos:}

\begin{tabular}{|l|l|}
\hline Formula & Quantity for $100 \mathrm{~g}$ \\
\hline $\begin{array}{l}\text { Ammonium lauryl alcohol } \\
\text { sulphate (surfactant) }\end{array}$ & $30 \mathrm{~g}$ \\
\hline $\begin{array}{l}\text { Coco diethanolamide } \\
\text { (pearlescent stabilizer ) }\end{array}$ & $2 \mathrm{~g}$ \\
\hline Water (solvent) & To make up to $100 \mathrm{~g}$ \\
\hline
\end{tabular}

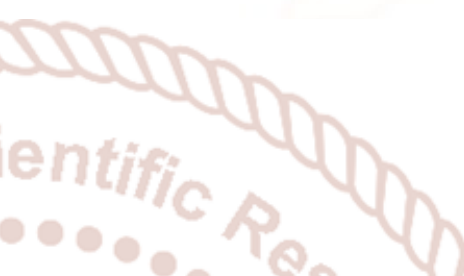

(i) O-nitro anilines. (Gives yellow and orange shades)

(ii) Aminonitrophenols and their ethers (gives yellow and orange shades)

(iii) Azo dyes (Gives yellow and orange shades)

(iv) Nitrodiphenylamines (Gives 'orange to red shades).

(v) Nitrophenyienediamines (Gives colour in the range red to violet).

(vi) Anthraquinone (Gives violet to blue shades).

5. Natural dyes: Since, antiquity, plant materials are looked upon as beneficial sources for

various ailments and other purposes. The leaves are used as colourants:'[22-23]

\begin{tabular}{|l|l|}
\hline \multicolumn{1}{|c|}{ Formula } & Quantity for $100 \mathrm{~g}$ \\
\hline Powdered henna (color) & $89 \mathrm{~g}$ \\
\hline Pyrogallic acid (color) & $6 \mathrm{~g}$ \\
\hline Copper sulphate (color) & $5 \mathrm{~g}$ \\
\hline
\end{tabular}


International Journal of Trend in Scientific Research and Development (IJTSRD) ISSN: 2456-6470

\section{CLASSIFICATION OF COMMERCIAL DYE}

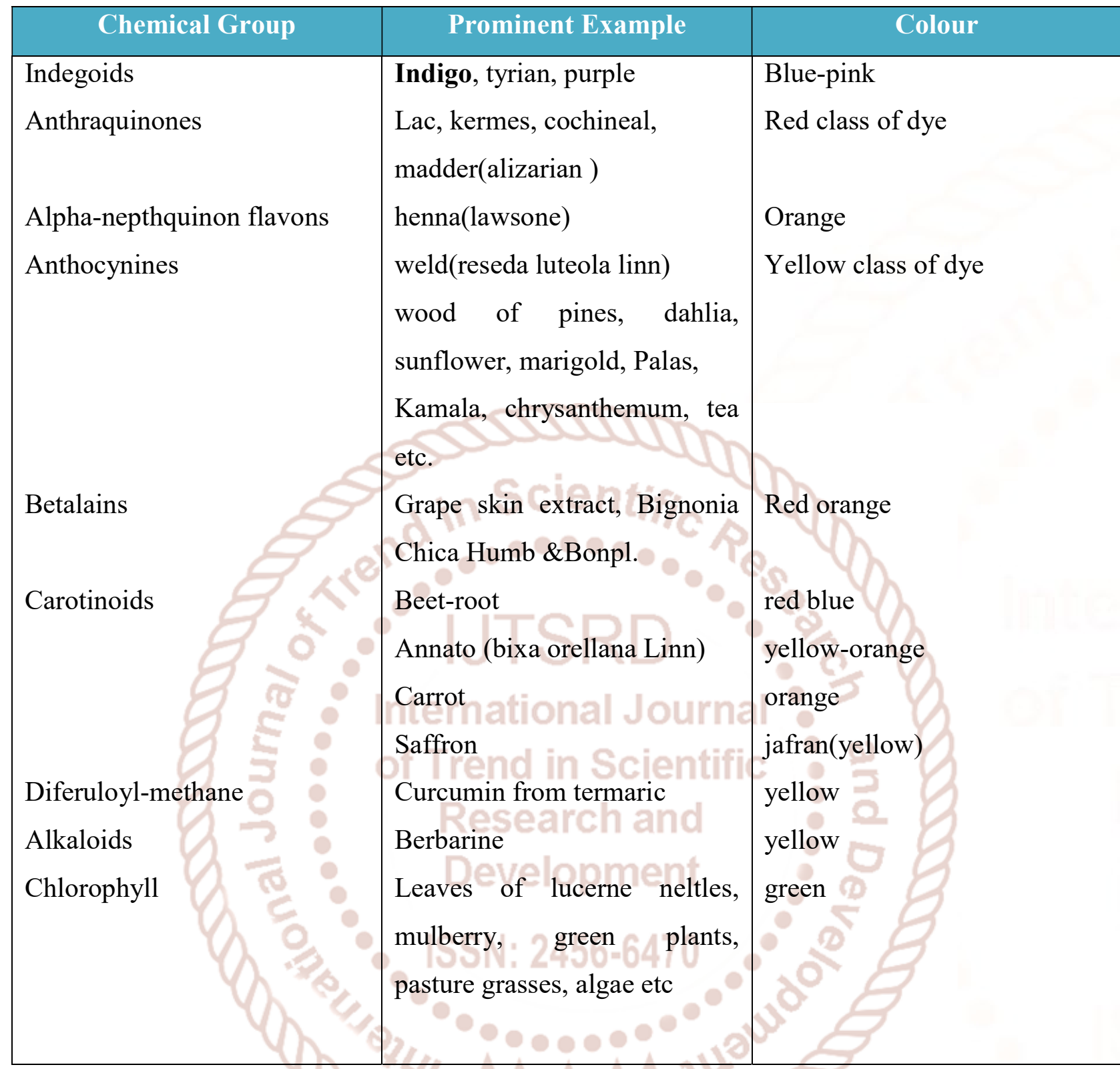

BOTANICAL USEFULL FOR HAIR CARE:

\begin{tabular}{|c|c|c|c|}
\hline S.no & $\begin{array}{c}\text { Botanical/common } \\
\text { name\& family }\end{array}$ & Used & \\
\hline 1. & Brassca spp,(mustard) & Seed oil is used as hair oil \\
& Brassicaceac & and useful for hair \\
2. & Acacia concinna Dc & nourishment. \\
& (shikakai), mimosaceae & cleanser and for control of & dandruff. \\
3. & Arnica Montana (Arnica), & Flower extract is used as hair & \\
\hline
\end{tabular}


International Journal of Trend in Scientific Research and Development (IJTSRD) ISSN: 2456-6470

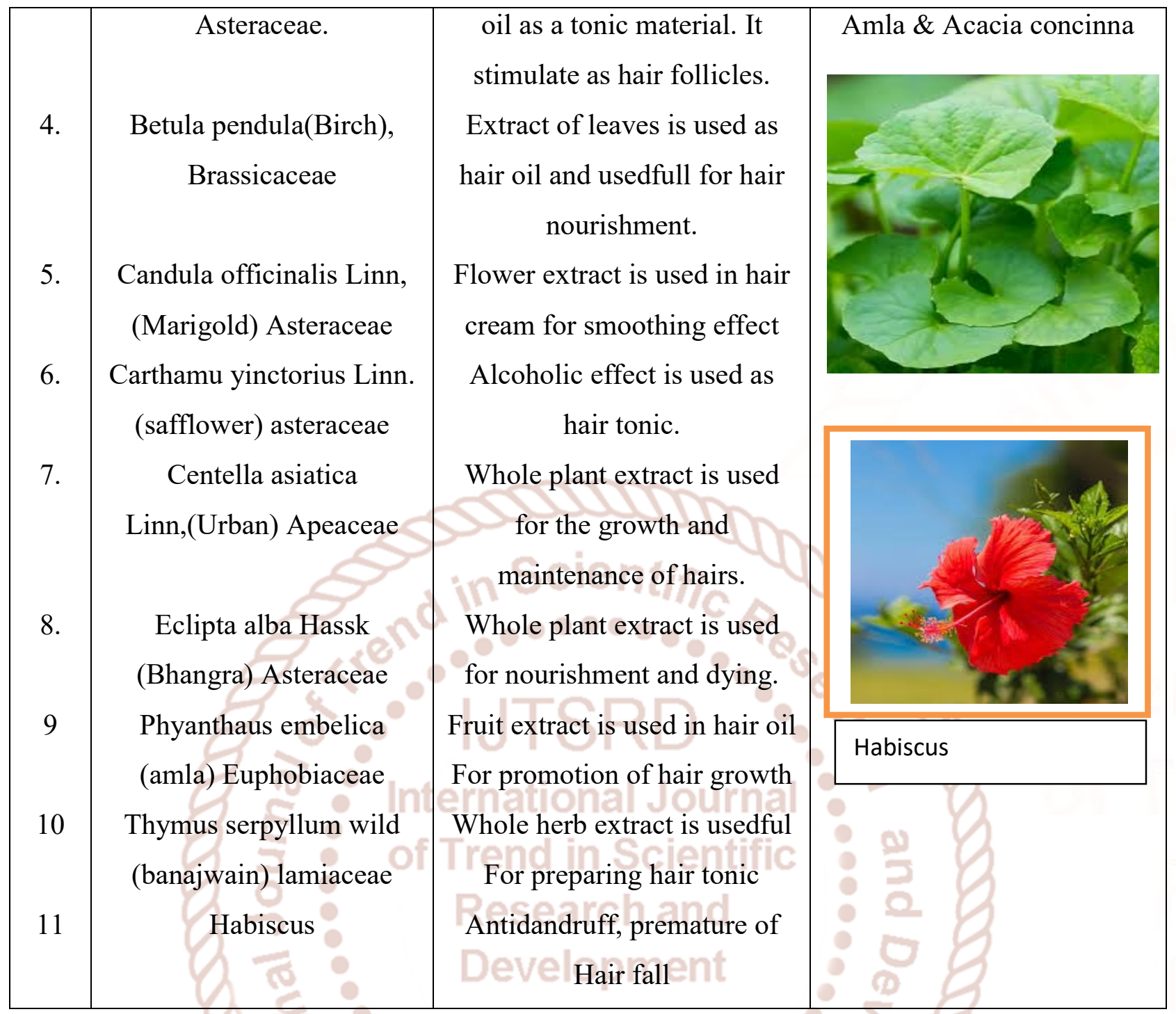

\section{Conclusion:}

The used of cosmetic has been increased many folds in personal care system and there is great demand in the market. so, this review could be the basic improvement and formulation of hair research.

\section{REFERENCE:}

1) The human hair: anatomy and physiology, Article: Literature review, December 2013 with 13, 933read.

2) Anatomy of hair article, in pubMed will retrieve 28879 records.int j Darmatol.2014 Mar, 53(3):33141. Doi: 10.1111/ijd12362Epub 2013 Dec30

3) www.springer.com $>$ content $>$ document

4) human hair https://en.m.wikipidia.org

\section{5) African
https:/afrisciheroes.wordpress.com.}

Heroes.

6) Hair Cosmetics, International journal of Trichology wolter kulwer, Medknow publication.

7) https://causesofhaircolors.weebly.com

8) webMD Medical Reference from the American Hair Loss Association, hairgrowcycle publish onmarch 1,2010

9) https://biology.seackexchange.com

"human biology" 30-jan-2015

10) https://www.naturallycurly.com. "Hair porosity"

11) Fredell, W.G., and Powers, D.H.: Factors attributing to the performance of shampoos and to consumer acceptance, Proc. Sci. Sec., 1955.

12) Rajkumar, K. J., Invitro evaluation of shampoos. 
13) Ross, J., and Miles, G.D.: An application for comparison of foaming properties of soaps and detergents, Oil and Soap, 1941.

14) A-sasutjarit R, Sirivat A, Vayumhasuwan $P$. Viscoelastic properties of Carbopol 940 gels and their relationships to piroxicam diffusion coefficients in gel bases. Pharm Res 2005; 22:2134-2140.

15) 16.Barreiro-Iglesias R, Alvarez-Lorenzo C, Concheiro A. Incorporation of small quantities of surfactants as a way to improve the rheological and diffusional behaviour of carbopol gels. J Contr Rel 2001; 77:59-75.

16) Barry BW, Dermatological Formulations, Percutaneous Absorption. New York: Marcel Dekker, 1983.

17) Berardesca E, Distante F. The modulation of skin irritation. Contact Dermat 1994; 31:281-287.

18) Mittal,: A Handbook of Cosmetics

19) www.cosmeticdatabase.com

20) Piyush, GPAT 2017, third ter revised edition:formation of shampoo.

21) Texbook of cosmetic formulation by Gaurav Sharma,jayesh gadiya, meenakshi dhanawat.

22) Balsam, S.M., Gershon, S.D., Rieger, M.M., Sagarin, E., and Strianse, S.J.: COSMETICSScience and Technology, 2nd edition, Vol-2, John Wiley India, New Delhi, 2008.

23) Classification of commercial dye and botanical useful of hair care: national botanical research institude,lakhnow by VK.kapoor'herbel cosmetic for skin and hair care"

24) Scartezzini P and speroni E, Review on some plants of Indian traditional medicine with antioxidant activity, J Ethnepharmacol,2000,71,23-43.

25) Thakur RS Puri HS and Hussain A,IN:Major Medicinal plants of India, 1989,CIMAP,lucknow. 